\title{
Some Elastic Compliances of Single Crystal Rutile From 25 to $1000{ }^{\circ} \mathrm{C}$
}

\author{
S. Spinner and J. B. Wachtman, Jr.
}

(August 4, 1964)

\begin{abstract}
Young's modulus, as a function of temperature up to $1000{ }^{\circ} \mathrm{C}$, was determined for eight rutile specimens of different crystallographic orientations. From these, the following four elastic compliances or combinations of them were determined as a function of temperature, $s_{11}, s_{33}, 2 s_{13}+s_{44}$, and $s_{11}-s_{12}-s_{66} / 2$. The method used was the same as had been used in a previous study for rutile at room temperature.
\end{abstract}

\section{Introduction}

In a previous investigation [1], ${ }^{1}$ all the elastic constants of rutile were determined at room temperature by an application of the resonance technique. Briefly, the method of approach consists in determining the mechanical resonance frequencies of both flexural and torsional vibration of a group of cylindrical rods of different orientations of the same type of crystal. Young's and the shear modulus are computed for each bar from these frequencies and from its dimensions and density. Then, from a set of equations given by Nye [2], for instance, relating Young's and the shear modulus to orientation and elastic compliances, one solves for the elastic compliances (since the other parameters, Young's modulus, shear modulus and orientation are known).

The number of equations required in the set, and, hence, also the number of specimens of different orientation, depends upon the number of elastic constants required to completely describe a particular crystal. If more than the minimum number of specimens are available, then, from an overdetermined set of equations, one may obtain an estimate of the precision of measurement of the elastic constants as well as the elastic constants themselves. This has been done for corundum [3] as well as rutile [1].

In this paper, some of the elastic compliances already determined at room temperature for rutilethose arising from the flexural resonance frequencies - are extended to elevated temperatures using the same method of approach. As far as we know, there is no data available on the temperature dependence of any of the elastic properties of rutile. paper.

1 Figures in brackets indicate the literature references at the end of this

\section{Experimental Procedure}

The method for obtaining resonance frequencies, both at room and elevated temperatures, has already been described [4-6]. However, certain refinements (such as the use of fine wires of phosphor bronze as suspension members) which were developed to obtain torsional resonance for the shorter rutile specimens [1] were not applicable at elevated temperatures. Furthermore, with the glass and wire fibers used at elevated temperatures as suspension members in place of the cotton or silk threads used at room temperature, it was not possible (mainly because of the small cross section of the specimens) to obtain satisfactory torsional resonances even for the longer specimens. Consequently, this investigation is restricted to the flexural resonance frequencies and to those elastic compliances which can be derived from them, as mentioned above.

For this purpose, 8 of the original 16 specimens were used. This included all of the longer ones (which yielded the most reliable values of resonance frequency) and those of the shorter ones having orientations which would be most significant in giving a Young's modulus-orientation relationship. The specimens used, along with their length, mass, and orientation, are given in table 1 . The same notation for designating specimens and orientation, as well as most of the other notation used in the previous paper [1] is retained here.

Flexural resonance frequencies for each specimen were determined in steps of about $100{ }^{\circ} \mathrm{C}$, allowing: sufficient time for thermal equilibrium to be attained at each temperature. Usually two or three sets of temperature determinations were taken for each specimen. The glass fiber suspensions (which yielded the more reliable results) were used for all the speci- 
mens up to the limit of their applicability; from 700 to $800{ }^{\circ} \mathrm{C}$. The wire suspensions gave satisfactory responses with the longer specimens up to the highest temperatures of the furnace, about $1400^{\circ} \mathrm{C}$, but were unsatisfactorv for two of the smaller specimens over about $800{ }^{\circ} \mathrm{C}$. Since the changes in elastic compliances were fairly gradual and continuous with temperature, it was felt to be a more accurate procedure to extrapolate the values obtained with the glass suspension for these two specimens up to 1000 ${ }^{\circ} \mathrm{C}$ rather than use the data obtained with the wire suspension.

Table 1. Properties of "single crystal" rutile specimens

\begin{tabular}{|c|c|c|c|c|c|c|c|c|}
\hline \multirow[b]{2}{*}{$\begin{array}{c}\text { Speci- } \\
\text { men } \\
\text { number }\end{array}$} & \multirow[b]{2}{*}{ Mass } & \multirow[b]{2}{*}{ Length } & \multicolumn{2}{|c|}{ End } & \multicolumn{2}{|c|}{ Center } & \multicolumn{2}{|c|}{ Other end } \\
\hline & & & $\theta$ & $\phi$ & $\theta$ & $\phi$ & $\theta$ & $\phi$ \\
\hline
\end{tabular}

\begin{tabular}{|c|c|c|c|c|c|c|c|c|}
\hline \multicolumn{9}{|c|}{ Linde rods } \\
\hline 21 & 2. $\stackrel{g}{6} 6317$ & $\begin{array}{c}c m \\
13.236\end{array}$ & 12.5 & $\begin{array}{l}2.6 \\
2 .\end{array}$ & 12.7 & 2.1 & $\left\{\begin{array}{l}14.3 \\
14.2\end{array}\right.$ & 1. 8 \\
\hline 23 & 2. 8205 & 12. 168 & 14. 0 & 7.3 & 16.1 & 7.0 & 14. 8 & $\begin{array}{l}1.0 \\
6.3\end{array}$ \\
\hline 24 & 2. 3654 & 11. 714 & 43.3 & 34.1 & 45. 6 & 37. 9 & 44.7 & 33. 6 \\
\hline 30 & 1. 1523 & 5.816 & 58.7 & 24.0 & 58.5 & 24.2 & 59.3 & 23.7 \\
\hline 44 & 15. 0251 & 9.848 & 88.8 & 44.1 & 88.4 & 43.4 & 90.0 & 44.5 \\
\hline
\end{tabular}

\begin{tabular}{|c|c|c|c|c|c|c|c|c|}
\hline \multicolumn{9}{|c|}{ NBS rods } \\
\hline 49 & 7. 1208 & 11.128 & 87.8 & 0.0 & 87.8 & 0.0 & 88.0 & 1.5 \\
\hline 50 & 21. 5907 & 17. 107 & 88.8 & 5. 4 & 89. 5 & 5. 4 & 90.0 & 5. 0 \\
\hline 51 & 16. 0263 & 17. 634 & 86.2 & 0.4 & 86.2 & 1.0 & 86.8 & 0.9 \\
\hline
\end{tabular}

Young's modules at some elevated temperature, $Y_{t}$, was computed from the resonance frequencies, from the equation

$$
Y_{t}=Y_{0}\left(f_{t} / f_{0}\right)^{2}\left(l_{t} / l_{0}\right)^{3}\left(m_{0} / m_{t}\right)\left(n_{0} / n_{t}\right)^{3} .
$$

The room temperature value of Young's modulus, $Y_{0}$, is known from the previous investigation; $f_{t}$ and $f_{0}$ are the flexural resonance frequencies at temperature $t$ and room temperature respectively. It should be noted that the ratio, $f_{t} / f_{0}$, applies to overtones as well as to the fundamental resonance frequency. This was used for the longer specimens to provide additional points (obtained from overtones as well as the fundamental) during a modulustemperature run. The points based on overtones also served as an internal check on the consistency of the modulus-temperature relationship. The terms involving $l, m$, and $n$ are the correction for thermal expansion. Since the thermal expansion of rutile is anisotropic, the coefficient being about 30 percent larger in the " $c$ " or [001] direction than in the " $a$ " or [100] direction, it was necessary to take this into account in a manner which has already been described [7]. The length of the long axis of the specimen at temperature $t$ is $l_{t}$, and $l_{0}$ is the same dimension at room temperature; similarly for $m$ and $n, n$ being the cross-sectional dimension in the direction of flexural vibration and $m$ being the crosssectional dimension perpendicular to $n$. A more detailed description of the application of this anisotropic thermal expansion correction to rutile is given in the appendix. Actual values of the thermal expansion of rutile in both " $a$ " and " $c$ " directions were supplied by Richard K. Kirby of the NBS staff. The possibility that certain orientations might change with increasing temperature due to this anisotropic thermal expansion was also considered. However, it was found that even in the extreme case $\left(t=1000{ }^{\circ} \mathrm{C}\right.$ and $\left.\theta=45{ }^{\circ} \mathrm{C}\right)$ the change in orientation would be insignificant, i.e., less than $12^{\circ}$

The scatter of the experimental points of $Y_{t}$ as a function of temperature, based on repeated runs and (where used) on overtones, about a smooth curve drawn through the points was estimated to be about 5 parts per 1000 .

\section{Results}

Values of $1 / Y_{t}$ interpolated from the experimental data at even $100{ }^{\circ} \mathrm{C}$ temperature intervals for the 8 specimens measured are shown in table 2 . The data at $25{ }^{\circ} \mathrm{C}$ are from the previous investigation [1]. The compliances are obtained from eq (6) of [1],

$$
\begin{aligned}
1 / Y_{t}=s_{33}^{\prime}=s_{11} \sin ^{4} \theta & +s_{33} \cos ^{4} \theta+\left(2 s_{13}+s_{44}\right) \sin ^{2} \theta \cos ^{2} \theta \\
& +\frac{1}{2}\left(s_{12}-s_{11}+\frac{s_{66}}{2}\right) \sin ^{4} \theta \sin ^{2} 2 \phi
\end{aligned}
$$

This equation was solved by computer at each temperature $\left(100{ }^{\circ} \mathrm{C}, 200{ }^{\circ} \mathrm{C} . .1000{ }^{\circ} \mathrm{C}\right)$ in the same manner as before. It is noted that since 8 specimens are used and 4 coefficients are solved for, an overdetermined set of equations is still available from which, as previously mentioned, one may derive an estimate of the precision of the coefficients from a least square best fit, as well as the coefficients themselves. Table 3 presents the four elastic compliances along with their standard deviations, computed in this manner. The standard deviations of the compliances, especially at the lower temperatures, compare favorably with those computed at room temperature. As might be expected, these standard deviations tend to grow somewhat larger at the higher temperatures. The four coefficients are shown graphically as a function of temperature in figure 1.

Once the compliances are known, they may be resubstituted in equation (6) and "theoretical" or "computed" values of $1 / Y_{t}$ may be solved for at each temperature. The numbers associated with each value of $1 / Y_{t}$ in table 2 represents the difference between these "computed" values and the "experimental" or "observed" values given in the table. Following the same convention as before, a + sign indicates that the experimental value of $1 / Y_{t}$ is larger than the theoretical one and vice versa. 
TABLE 2. Reciprocal of Young's modulus for rutile specimens of various orientations as a function of temperature. $1 / Y_{t}=8_{33}^{1}$ in $10^{-12} \mathrm{~m}^{2} / \mathrm{N}\left(10^{-13} \mathrm{~cm}^{2} / \mathrm{dyne}\right)$ at indicated temperature $\left({ }^{\circ} \mathrm{C}\right)$

\begin{tabular}{|c|c|c|c|c|c|c|c|c|c|c|c|}
\hline Specimen No. & 25 & 100 & 200 & 300 & 400 & 500 & 600 & 700 & 800 & 900 & 1000 \\
\hline 21.... & 2. 666 & $\begin{array}{l}2.708 \\
.0005^{*}\end{array}$ & $\begin{array}{l}2.762 \\
.0015\end{array}$ & $\begin{array}{l}2.815 \\
-.0001\end{array}$ & $\begin{array}{c}2.871 \\
-.0003\end{array}$ & $\begin{array}{l}2.927 \\
-.0001\end{array}$ & $\begin{array}{c}2.986 \\
-.0016\end{array}$ & $\begin{array}{l}3.050 \\
-.0011\end{array}$ & $\begin{array}{l}3.108 \\
-.0023\end{array}$ & $\begin{array}{c}3.176 \\
-.0008\end{array}$ & $\begin{array}{c}3.241 \\
-.0016\end{array}$ \\
\hline $23 \ldots$ & 2. 690 & $\begin{array}{c}2.731 \\
-.0006\end{array}$ & $\begin{array}{c}2.783 \\
-.0012\end{array}$ & $\begin{array}{l}2.840 \\
-.0013\end{array}$ & $\begin{array}{c}2.895 \\
.0009\end{array}$ & $\begin{array}{l}2.950 \\
.0005\end{array}$ & $\begin{array}{l}\text { 3. } 011 \\
.0016\end{array}$ & $\begin{array}{l}3.072 \\
-.0005\end{array}$ & $\begin{array}{c}3.134 \\
.0019\end{array}$ & $\begin{array}{c}3.198 \\
-.0002\end{array}$ & $\begin{array}{l}3.263 \\
\quad-.0004\end{array}$ \\
\hline 24 & 3. 047 & $\begin{array}{l}\text { 3. } 092 \\
.0003\end{array}$ & $\begin{array}{l}3.147 \\
-.0013\end{array}$ & $\begin{array}{l}3.203 \\
-.0056\end{array}$ & $\begin{array}{c}3.257 \\
-.0029\end{array}$ & $\begin{array}{c}3.314 \\
-.0020\end{array}$ & $\begin{array}{c}3.373 \\
.0004\end{array}$ & $\begin{array}{c}3.444 \\
.0081\end{array}$ & $\begin{array}{l}3.512 \\
.0026\end{array}$ & $\begin{array}{l}3.580 \\
.0054\end{array}$ & $\begin{array}{l}3.647 \\
.0105\end{array}$ \\
\hline $30 \ldots$ & 3. 881 & $\begin{array}{c}3.921 \\
-.0003\end{array}$ & $\begin{array}{c}3.973 \\
.0017\end{array}$ & $\begin{array}{l}\text { 4. } 032 \\
-.0070\end{array}$ & $\begin{array}{l}\text { 4. } 074 \\
.0035\end{array}$ & $\begin{array}{l}4.125 \\
.0024\end{array}$ & $\begin{array}{c}4.175 \\
-.0006\end{array}$ & $\begin{array}{c}4.226 \\
-.0098\end{array}$ & $\begin{array}{l}4.303 \\
-.0032\end{array}$ & $\begin{array}{l}4.364 \\
-.0065\end{array}$ & $\begin{array}{l}4.423 \\
-.0128\end{array}$ \\
\hline $44 \ldots$ & 2. 694 & $\begin{array}{l}2.778 \\
.0001\end{array}$ & $\begin{array}{l}2.872 \\
-.0002\end{array}$ & $\begin{array}{c}2.960 \\
-.0006\end{array}$ & $\begin{array}{c}3.048 \\
-.0004\end{array}$ & $\begin{array}{c}3.135 \\
-.0003\end{array}$ & $\begin{array}{l}3.223 \\
.0001\end{array}$ & $\begin{array}{l}\text { 3. } 320 \\
.0011\end{array}$ & $\begin{array}{l}3.408 \\
.0003\end{array}$ & $\begin{array}{l}3.501 \\
.0007\end{array}$ & $\begin{array}{l}3.597 \\
.0019\end{array}$ \\
\hline 49_... & 6. 777 & $\begin{array}{c}6.777 \\
.0016\end{array}$ & $\begin{array}{c}6.779 \\
.0009\end{array}$ & $\begin{array}{c}6.798 \\
.0093\end{array}$ & $\begin{array}{l}6.800 \\
.0022\end{array}$ & $\begin{array}{l}6.820 \\
.0017\end{array}$ & $\begin{array}{c}6.846 \\
.0016\end{array}$ & $\begin{array}{c}6.877 \\
.0014\end{array}$ & $\begin{array}{l}6.922 \\
.0058\end{array}$ & $\begin{array}{c}6.964 \\
.0006\end{array}$ & $\begin{array}{l}7.047 \\
.0212\end{array}$ \\
\hline $50 \ldots$ & 6. 650 & $\begin{array}{c}6.651 \\
-.0010\end{array}$ & $\begin{array}{c}6.656 \\
-.0017\end{array}$ & $\begin{array}{c}6.665 \\
-.0057\end{array}$ & $\begin{array}{c}6.681 \\
-.0014\end{array}$ & $\begin{array}{c}6.704 \\
-.0010\end{array}$ & $\begin{array}{c}6.732 \\
-.0010\end{array}$ & $\begin{array}{l}6.769 \\
.0027\end{array}$ & $\begin{array}{l}6.812 \\
.0036\end{array}$ & $\begin{array}{c}6.859 \\
.0018\end{array}$ & $\begin{array}{c}6.911 \\
-.0096\end{array}$ \\
\hline $51 \ldots$ & 6.757 & $\begin{array}{c}6.755 \\
-.0006\end{array}$ & $\begin{array}{l}6.759 \\
.0004\end{array}$ & $\begin{array}{c}6.764 \\
-.0054\end{array}$ & $\begin{array}{c}\text { 6. } 777 \\
-.0017\end{array}$ & $\begin{array}{c}6.798 \\
-.0013\end{array}$ & $\begin{array}{c}6.825 \\
-.0005\end{array}$ & $\begin{array}{c}6.855 \\
-.0018\end{array}$ & $\begin{array}{c}6.889 \\
-.0086\end{array}$ & $\begin{array}{c}6.944 \\
-.0009\end{array}$ & $\begin{array}{c}6.998 \\
-.0092\end{array}$ \\
\hline
\end{tabular}

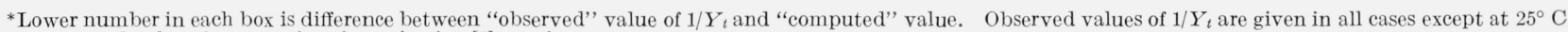
where computed values from previous investigation [1] are given.

TABLE 3. Elastic compliances of rutile as a function of temperature in $10^{-12} \mathrm{~m}^{2} / \mathrm{N}\left(10^{-13} \mathrm{~cm}^{2} /\right.$ dyne $)$

\begin{tabular}{|c|c|c|c|c|}
\hline Temperature & $S_{11}$ & $S_{33}$ & $2 S_{13}+S_{44}$ & $S_{11}-S_{12}-\frac{S_{66}}{2}$ \\
\hline $\begin{array}{l}{ }^{\circ} \mathrm{C} \\
25 \\
100 \\
200 \\
300 \\
400 \\
500 \\
600 \\
700 \\
800 \\
900 \\
1000\end{array}$ & $\begin{array}{l}6.787 \pm .0003^{*} \\
6.786 \pm .0006 \\
6.789 \pm .0010 \\
6.799 \pm .0040 \\
6.808 \pm .0016 \\
6.828 \pm .0012 \\
6.855 \pm .0009 \\
6.886 \pm .0039 \\
6.926 \pm .0035 \\
6.973 \pm .0026 \\
7.036 \pm .0088\end{array}$ & $\begin{array}{l}2.592 \pm .0004 \\
2.635 \pm .0010 \\
2.689 \pm .0015 \\
2.744 \pm .0066 \\
2.803 \pm .0024 \\
2.860 \pm .0017 \\
2.923 \pm .0013 \\
2.988 \pm .0058 \\
3.045 \pm .0052 \\
3.113 \pm .0038 \\
3.181 \pm .0131\end{array}$ & $\begin{array}{l}6.464 \pm .0016 \\
6.528 \pm .0039 \\
6.617 \pm .0063 \\
6.725 \pm .0273 \\
6.793 \pm .0099 \\
6.881 \pm .0071 \\
6.965 \pm .0056 \\
7.065 \pm .0238 \\
7.219 \pm .0217 \\
7.325 \pm .0157 \\
7.414 \pm .0540\end{array}$ & $\begin{array}{l}8.197 \pm .0011 \\
8.026 \pm .0056 \\
7.843 \pm .0041 \\
7.687 \pm .0178 \\
7.529 \pm .0065 \\
7.396 \pm .0046 \\
7.272 \pm .0036 \\
7.142 \pm .0155 \\
7.046 \pm .0141 \\
6.955 \pm .0103 \\
6.890 \pm .0353\end{array}$ \\
\hline
\end{tabular}

* Standard deviation.

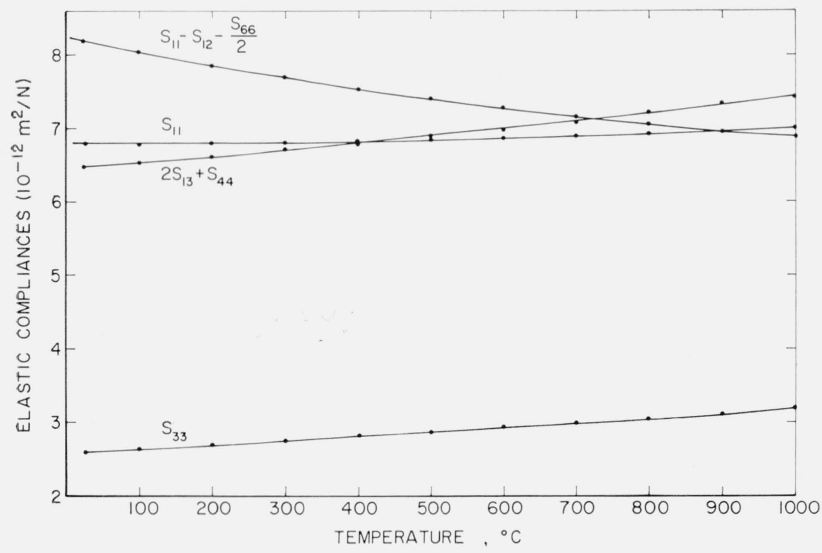

Figure 1. Elastic compliance of rutile as a function of temperature.

Figure 2 shows the Young's modulus-orientation dependence for rutile at two selected temperatures, $400{ }^{\circ} \mathrm{C}$ and $1000{ }^{\circ} \mathrm{C}$, obtained in the same manner as the room temperature curves, which are reproduced from the original study for comparison.

It may be seen from the figure that in addition to the expected decrease in modulus for all orientations with increasing temperature, the anisotropy of the crystal decreases also. For any given value of $\theta$, the change in Young's modulus, as a function of $\phi$, is less at $1000{ }^{\circ} \mathrm{C}$ than at $25^{\circ} \mathrm{C}$. Also, for any particular value of $\phi$, the variation in $\theta$ appears to decrease at the higher temperatures, i.e., the lines become flatter.

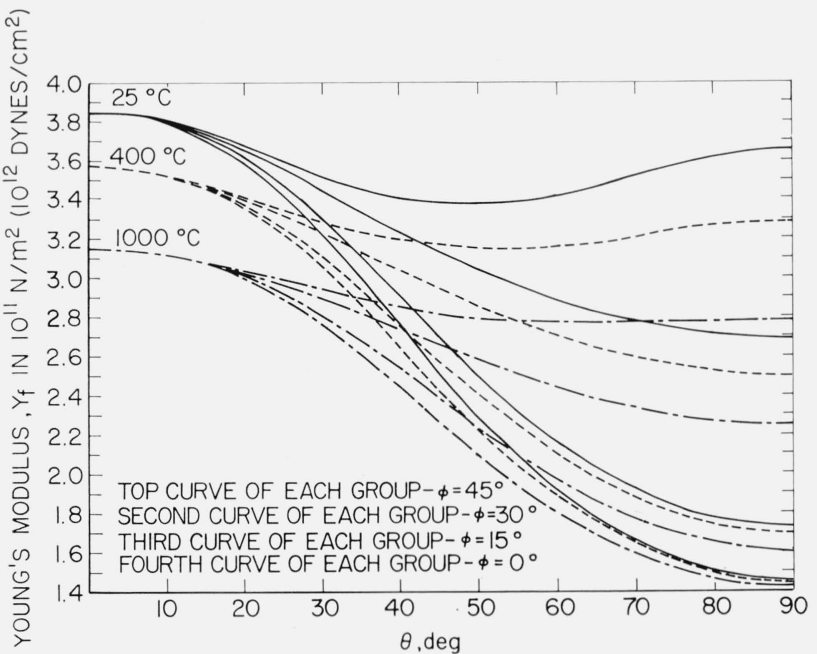

Figure 2. Young's modulus of rutile as a function of orientation at selected temperatures.

$\Theta$ is angle of specimen axis with respect to " $c$ " axis of crystal; $\phi$ is angle between the projection of specimen axis in (001) plane of crystal, and " $a$ " axis of crystal. (The subscript " $f$ " is retained in $Y_{f}$ from the previous investigation [1] to indicate the "free" rather than the "pure" modulus.) 


\section{Appendix}

The problem is to express eq (1) in terms of the known thermal expansions for rutile for given crystallographic directions. We define these two thermal expansions for the " $c$ " and " $a$ " directions respectively as $L_{t c} / L_{o c}$ and $L_{t a} / L_{o a}$.

(1) We consider first a " $c$ " axis rod, i.e., a specimen of which the long dimension is in the direction of the crystallographic "c" axis. For this condition,

$$
\frac{l_{t}}{l_{0}}=\frac{L_{t c}}{L_{0 c}} \text { and } \frac{m_{t}}{m_{0}}=\frac{n_{t}}{n_{0}}=\frac{L_{t a}}{L_{0 a}}
$$

so that equation (1) becomes

$$
Y_{t}=Y_{0}\left(\frac{f_{t}}{f_{0}}\right)^{2}\left(\frac{L_{t c}}{L_{0 c}}\right)^{3}\left(\frac{L_{0 a}}{L_{t a}}\right)^{4} .
$$

(2) We next consider an " $a$ " axis rod. In this case, since the thermal expansion of the crosssectional dimensions are not equal, a specimen having a circular cross section at room temperature will develop a noncircular cross section as the temperature increases. This will give rise to two separate flexural resonance frequencies; one in the direction of the short cross-sectional dimension, the " $a$ " direction, and the other in the direction of the long cross-sectional dimension, the "c" direction. These two types of vibration are considered separately. For vibrations along the " $a$ " direction,

$$
\frac{l_{t}}{l_{0}}=\frac{L_{t a}}{L_{0 a}}, \frac{m_{t}}{m_{0}}=\frac{L_{t c}}{L_{0 a}}, \text { and } \frac{n_{t}}{n_{0}}=\frac{L_{t a}}{L_{0 a}}
$$

(since " $n$ " is always the dimension in the direction of vibration). Equation (1) then becomes

$$
\begin{aligned}
& Y_{t}=Y_{0}\left(\frac{f_{t}}{f_{0}}\right)^{2}\left(\frac{L_{t a}}{L_{0 a}}\right)^{3}\left(\frac{L_{0 c}}{L_{t c}}\right)\left(\frac{L_{0 a}}{L_{t a}}\right)^{3} \\
& Y_{t}=Y_{0}\left(\frac{f_{t}}{f_{0}}\right)^{2}\left(\frac{L_{0 c}}{L_{t c}}\right) .
\end{aligned}
$$

For vibrations in the "cc" direction,

$$
\frac{l_{t}}{l_{0}}=\frac{L_{t a}}{L_{0 a}}, \frac{m_{t}}{m_{0}}=\frac{L_{t a}}{L_{0 a}}, \text { and } \frac{n_{t}}{n_{0}}=\frac{L_{t c}}{L_{0 a}}
$$

and eq (1) becomes

$$
\begin{aligned}
& Y_{t}=Y_{0}\left(\frac{f_{t}}{f_{0}}\right)^{2}\left(\frac{L_{t a}}{L_{0 a}}\right)^{3}\left(\frac{L_{0 a}}{L_{t a}}\right)\left(\frac{L_{0 c}}{L_{t c}}\right)^{3} \\
& Y_{t}=Y_{0}\left(\frac{f_{t}}{f_{0}}\right)^{2}\left(\frac{L_{t a}}{L_{0 a}}\right)^{2}\left(\frac{L_{0 c}}{L_{t c}}\right)^{3} .
\end{aligned}
$$

It is clear that any specimen having its long axis in the $(001)$ plane $\left(\theta=90^{\circ}, \varphi\right.$ from 0 to $\left.45^{\circ}\right)$ will have the same thermal expansion corrections as the two just given, since the same considerations holding for an " $a$ " axis rod would apply.
It also follows from these considerations that rods having their long axis in the (001) plane should develop two noticeably different curves of $\left(f_{t} / f_{0}\right)^{2}$ as a function of temperature. This was observed experimentally; however, when the appropriate thermal expansion correction was applied to the points forming each curve (giving $Y_{t} / Y_{0}$ as a function of temperature), the two curves were brought into coincidence within experimental error. Conversely, for " $c$ " axis rods, it was observed that even if two resonance frequencies were present at room temperature, due to the fact that the cross section was not perfectly circular (at room temperature), nevertheless, the two curves of $\left(f_{t} / f_{0}\right)^{2}$ as a function of temperature, based on these two room temperature resonance frequencies, coincided within experimental error. This was further verification of the validity of the thermal expansion corrections.

(3) The final case to be considered is that of a rod having its long axis at some angle, $\theta$, with the " $c$ " axis. In this case, since the " $c$ " axis does not coincide with any specimen axis $(l, m$, or $n)$ as has been true in the previous examples, the thermal expansions along $l, m$, or $n$ will generally not equal $L_{t c} / L_{n c}$ or $L_{t a} / L_{\mathrm{o} a}$, but will lie between these values. The following equation [7] then applies,

$$
\begin{aligned}
\frac{Y_{t}}{Y_{0}}=\left(\frac{f_{t}}{f_{0}}\right)^{2}\left\{1-\frac{\Delta L_{a}}{L_{a}}+\right. & \left(\frac{\Delta L_{c}}{L_{c}}-\frac{\Delta L_{a}}{L_{a}}\right) \\
& {\left.\left[3 \cos ^{2} \theta-\sin ^{2} \theta\left(1+2 \cos ^{2} \psi\right)\right]\right\} }
\end{aligned}
$$

where $\psi$ is the angle between the direction of vibration and the plane containing the "c" axis and the long axis of the rod. If this equation is written for each of the two directions of vibration, and the average of these two equations is taken, the following relationship results:

$$
\begin{aligned}
Y_{t}=Y_{0}\left(\frac{f_{t}}{f_{0}}\right)_{\text {ave. }}^{2}\left\{1-\frac{\Delta L_{a}}{\Delta L_{a}}\right. & \\
+ & \left.+\left(\frac{\Delta L_{c}}{L_{c}}-\frac{\Delta L_{a}}{L_{a}}\right)\left[3-5 \sin ^{2} \theta\right]\right\} .
\end{aligned}
$$

This final equation is also applicable to the specialized orientations previously discussed. It is useful for the case in which the long axis of the rod coincides with the [001] direction or lies in the (001) plane, but in which the direction of vibration does not coincide with a crystallographic axis.

\section{References}

[1] J. B. Wachtman, Jr., W. E. Tefft, and D. G. Lam, Jr., Elastic constants of rutile $\left(\mathrm{TiO}_{2}\right)$, J. Res. NBS $\mathbf{6 6 A}$, (Phys. and Chem.), No. 6, 465-471 (1962).

[2] J. F. Nye, Physical Properties of Crystals (Oxford Univ. Press. London, England, 1957).

[3] J. B. Wachtman, Jr., W. E. Tefft, D. G. Lam, Jr., and R. P. Stinchfield, Elastic constants of synthetic single crystal corundum at room temperature, J. Res. NBS 64A (Phys. and Chem.), No. 3 213-228 (1960). 
[4] S. Spinner and W. E. Tefft, A Method for determining mechanical resonance frequencies and for calculating elastic moduli from these frequencies, Proc. ASTM 61, 1221-1237 (1961).

[5] J. B. Wachtman, Jr., and D. G. Lam, Jr., Young's Modulus of various refractory materials as a function of temperature, J. Am. Ceram. Soc. 42, 5, 254 (1959).
[6] Sam Spinner, Temperature dependence of elastic constants of some cermet specimens, J. Res. NBS 65C (Eng. and Instr.), No. 2, 89-96 (1961).

[7] J. B. Wachtman, Jr., W. E. Tefft, D. G. Lam. Jr., and C. S. Apstein, Exponential temperature dependence of Young's modulus for several oxides, Phys. Rev. 122, No. 6, 1754-1759 (1961).

(Paper 68A6-316) 